\title{
Biological caproate production by Clostridium kluyveri from ethanol and acetate as
} carbon sources

Yin, Yanan; Zhang, Yifeng; Karakashev, Dimitar Borisov; Wang, Jianlong; Angelidaki, Irini

Published in:

Bioresource Technology

Link to article, DOI:

10.1016/j.biortech.2017.05.184

Publication date:

2017

Document Version

Peer reviewed version

Link back to DTU Orbit

Citation (APA):

Yin, Y., Zhang, Y., Karakashev, D. B., Wang, J., \& Angelidaki, I. (2017). Biological caproate production by Clostridium kluyveri from ethanol and acetate as carbon sources. Bioresource Technology, 241, 638-644. https://doi.org/10.1016/j.biortech.2017.05.184

\section{General rights}

Copyright and moral rights for the publications made accessible in the public portal are retained by the authors and/or other copyright owners and it is a condition of accessing publications that users recognise and abide by the legal requirements associated with these rights.

- Users may download and print one copy of any publication from the public portal for the purpose of private study or research.

- You may not further distribute the material or use it for any profit-making activity or commercial gain

- You may freely distribute the URL identifying the publication in the public portal 


\section{Accepted Manuscript}

Biological caproate production by Clostridium kluyveri from ethanol and acetate as carbon sources

Yanan Yin, Yifeng Zhang, Dimitar Borisov Karakashev, Jianlong Wang, Irini Angelidaki

PII:

S0960-8524(17)30852-0

DOI: http://dx.doi.org/10.1016/j.biortech.2017.05.184

Reference:

BITE 18210

To appear in:

Bioresource Technology

Received Date:

20 April 2017

Revised Date:

26 May 2017

Accepted Date:

27 May 2017

Please cite this article as: Yin, Y., Zhang, Y., Karakashev, D.B., Wang, J., Angelidaki, I., Biological caproate production by Clostridium kluyveri from ethanol and acetate as carbon sources, Bioresource Technology (2017), doi: http://dx.doi.org/10.1016/j.biortech.2017.05.184

This is a PDF file of an unedited manuscript that has been accepted for publication. As a service to our customers we are providing this early version of the manuscript. The manuscript will undergo copyediting, typesetting, and review of the resulting proof before it is published in its final form. Please note that during the production process errors may be discovered which could affect the content, and all legal disclaimers that apply to the journal pertain. 


\section{$1 \quad$ Biological caproate production by Clostridium kluyveri}

\section{2 from ethanol and acetate as carbon sources}

3 Yanan Yin ${ }^{\mathrm{a}}$, Yifeng Zhang ${ }^{\mathrm{b} *}$, Dimitar Borisov Karakashev ${ }^{\mathrm{b}, \mathrm{c}}$, Jianlong Wang ${ }^{\mathrm{a}}$, Irini

$4 \quad$ Angelidaki ${ }^{\mathrm{b}}$

5 a. Collaborative Innovation Center for Advanced Nuclear Energy Technology, INET,

6 Tsinghua University, Beijing 100084, PR China

7 b. Department of Environmental Engineering, Technical University of Denmark,

8 DK-2800 Lyngby, Denmark

9 c. Current address: Bioressources and Biorefinery, AgroTech, Danish Technological

10 Institute, Gregersensvej, 2630 Taastrup, Denmark 


\section{Abstract}

12 Caproate is a valuable industrial product and chemical precursor. In this study, batch

13 tests were conducted to investigate the fermentative caproate production through

14 chain elongation from acetate and ethanol. The effect of acetate/ethanol ratio and

15 initial ethanol concentration on caproate production was examined. When substrate

16 concentration was controlled at $100 \mathrm{mM}$ total carbon, hydrogen was used as an

17 additional electron donor. The highest caproate concentration of $3.11 \mathrm{~g} / \mathrm{L}$ was

18 obtained at an ethanol/acetate ratio of 7:3. No additional electron donor was needed

19 upon an ethanol/acetate ratio $\geq 7: 3$. Caproate production increased with the increase of

20 carbon source until ethanol concentration over $700 \mathrm{mM}$, which inhibited the

21 fermentation process. The highest caproate concentration of $8.42 \mathrm{~g} / \mathrm{L}$ was achieved

22 from high ethanol strength wastewater with an ethanol/acetate ratio of 10:1 (550 mM

23 total carbon). Results obtained in this study can pave the way towards efficient chain

24 elongation from ethanol-rich wastewater.

25 Keywords: Chain elongation; n-caproate, Clostridium kluyveri; Fermentation;

26 Ethanol/acetate ratio 


\section{Introduction}

28 For a sustainable development, production of biochemicals and biofuels from biomass

29

by fermentation has become a priority. Examples of such products are ethanol, biohydrogen and biomethane. Besides the final products, intermediate compounds are also produced. Such compounds are volatile fatty acids (VFA) with 2 to 5 carbon atoms which are formed during fermentation processes and often accumulate in the liquid phase (Lee et al., 2014; Yang et al., 2015; Yin and Wang, 2016). Discharge of these metabolites into environment will not only lead to pollution but also waste energy, since they could be used as precursor for biofuels. However, the high solubility of short-chain fatty acids makes them hard to be recovered and therefore the downstream processing for retrieving these intermediates has been the main reason hampering their further maturation as market products. Furthermore, they are inappropriate to be used as fuel directly owing to the high oxygen-to-carbon ratio and low energy density (Steinbusch, 2011). On the other hand, medium-chain fatty acids (carboxylic acids with 6 to 8 carbon atoms), which own the advantage of both low solubility and high energy content, are regarded as potential intermediates for further conversion to valuable chemicals or fuels (Levy et al., 1981).

Caproic acid is a six-carbon acid with the general formula $\mathrm{C}_{5} \mathrm{H}_{11} \mathrm{COOH}$. It is a fatty acid naturally present in various animal fats and oils. Caproic acid is slightly soluble in water $(10.19 \mathrm{~g} / \mathrm{L})$, thus, converting short-chain fatty acids to caproic acid can lead to efficient downstream recovery of liquid metabolites from fermentation process (Agler et al., 2014). It is not only a valuable industrial product but also a chemical precursor. It 
can be used as a "green" antibiotic in agriculture at lower $\mathrm{pH}$ levels $(\mathrm{pH}$ 2.0-5.0)

(Butkus et al., 2010; Agler et al., 2011; P. Desbois, 2012). Caproic acid is also a precursor for the production of flavors (Kenealy et al., 1995), liquid fuels (Harvey and Meylemans, 2014) and corresponding alcohols (Perez et al., 2013; Isom et al., 2015).

Moreover it is an important flavor compound in distilled alcoholic beverage (Hu et al., 2015).

Caproate has been found as a byproduct of fermentative hydrogen or methane production from organic wastes (Steinbusch et al., 2009; Ding et al., 2010), which may be produced from the elongation of VFA present in the system. Then, several studies have followed up this assumption and explored chain elongation process by using different substrates (e.g., syngas) or process configurations (Steinbusch et al., 2011;

Grootscholten et al., 2013; Kucek et al., 2016; Gildemyn et al., 2017). It has been observed that a group of anaerobic bacteria that possess fatty acid synthase complex are able to elongate ethanol and short chain fatty acids through a reaction known as the reversed $\beta$-oxidation. Several bacteria such as Clostridium species have been reported to be able to produce caproic acid from short chain fatty acids (Thauer et al., 1968; Seedorf et al., 2008; Weimer and Stevenson, 2012); Among all the species able to produce caproate, spore forming Clostridium kluyveri has been ubiquitously identified in anaerobic fermentation systems, and proved to be efficient in converting ethanol and acetate to butyrate and caproate (Ding et al., 2010). Thus, C. kluyver was used in this study to explore the caproate production from different concentrations of ethanol and acetate. Equation 1-3.4 shows several metabolic pathways that have been 
71 suggested for caproate formation in anaerobic fermentation (Ding et al. 2010; Mu and

72 Yu, 2006).

$732 \mathrm{C}_{2} \mathrm{H}_{5} \mathrm{OH}+\mathrm{CH}_{3} \mathrm{COO}^{-} \rightarrow \mathrm{C}_{5} \mathrm{H}_{11} \mathrm{COO}^{-}+2 \mathrm{H}_{2} \mathrm{O} \quad \Delta \mathrm{G}^{0}=-79.0 \mathrm{~kJ} / \mathrm{mol}$

$3 \mathrm{CH}_{3} \mathrm{COO}^{-}+4 \mathrm{H}_{2}+2 \mathrm{H}^{+} \rightarrow \mathrm{C}_{5} \mathrm{H}_{11} \mathrm{COO}^{-}+4 \mathrm{H}_{2} \mathrm{O} \quad \Delta \mathrm{G}^{0}=-86.2 \mathrm{~kJ} / \mathrm{mol}$

$\mathrm{C}_{2} \mathrm{H}_{5} \mathrm{OH}+\mathrm{CH}_{3} \mathrm{COO}^{-} \rightarrow \mathrm{C}_{3} \mathrm{H}_{7} \mathrm{COO}^{-}+\mathrm{H}_{2} \mathrm{O} \quad \Delta \mathrm{G}^{0}=-38.7 \mathrm{~kJ} / \mathrm{mol}$

$2 \mathrm{C}_{3} \mathrm{H}_{7} \mathrm{COO}^{-} \rightarrow \mathrm{C}_{5} \mathrm{H}_{11} \mathrm{COO}^{-}+\mathrm{CH}_{3} \mathrm{COO}^{-} \quad \Delta \mathrm{G}^{0}=0.1 \mathrm{~kJ} / \mathrm{mol}$

$\mathrm{C}_{3} \mathrm{H}_{7} \mathrm{COO}^{-}+\mathrm{CH}_{3} \mathrm{COO}^{-}+2 \mathrm{H}_{2}+\mathrm{H}^{+} \rightarrow \mathrm{C}_{5} \mathrm{H}_{11} \mathrm{COO}^{-}+2 \mathrm{H}_{2} \mathrm{O} \quad \Delta \mathrm{G}^{0}=-48.0 \mathrm{~kJ} / \mathrm{mol}$

$\mathrm{C}_{3} \mathrm{H}_{7} \mathrm{COO}^{-}+2 \mathrm{C}_{2} \mathrm{H}_{5} \mathrm{OH} \rightarrow \mathrm{C}_{5} \mathrm{H}_{11} \mathrm{COO}^{-}++\mathrm{CH}_{3} \mathrm{COO}^{-}+\mathrm{H}^{+}+2 \mathrm{H}_{2} \quad \Delta \mathrm{G}^{0}=-48.4 \mathrm{~kJ} / \mathrm{mol}$

$\mathrm{C}_{3} \mathrm{H}_{7} \mathrm{COO}^{-}+2 \mathrm{CO}_{2}+6 \mathrm{H}_{2} \rightarrow \mathrm{C}_{5} \mathrm{H}_{11} \mathrm{COO}^{-}+4 \mathrm{H}_{2} \mathrm{O} \quad \Delta \mathrm{G}^{0}=-143.3 \mathrm{~kJ} / \mathrm{mol}$

$\Delta \mathrm{G}^{0}(\mathrm{~kJ} / \mathrm{mol})$ is the value of $\Delta \mathrm{G}$ at $\mathrm{pH} 7.0$ under standard conditions (i.e., all solutes are at the concentration of $1 \mathrm{~mol} / \mathrm{L}$, and gases have partial pressure of $1 \mathrm{~atm}$ ). dependent upon concentration of acetate and ethanol, and the excess of ethanol can lead to more caproate yield than butyrate. Similar conclusion was also obtained by Kenealy and Waselefsky (1985). Weimer et al. (2012) examined the effect of different acetate and ethanol concentrations on products formation, and highest caproate production was obtained at ethanol $700 \mathrm{mM}$ and acetate $120 \mathrm{mM}$. Besides, Kenealy

88 and Waselefsky (1985) observed the linear response of both products and microbial

89 growth with ethanol and acetate concentration up to 200 and $50 \mathrm{mM}$, and Weimer et al.

90 (2012) found that a further increase of ethanol or acetate concentration can lead to a

91 significant decrease on $C$. kluyver growth rate. These studies show the significant

92 influence of acetate/ethanol ratios on products, and the contradictory effect of substrate 
concentration on caproate production and microbial growth. Thus, to achieve a high caproate production, it is necessary to break through the substrate inhibition and supply a suitable acetate/ethanol ratio.

In the past few years, most studies have reported production of caproate only from low ethanol concentration $(<300 \mathrm{mmol} / \mathrm{L})$ because ethanol is inhibitory to microorganisms (Kenealy et al., 1995; Jeon et al., 2010; Weimer and Stevenson, 2012; Vasudevan et al., 2014; Weimer et al., 2015). As a consequence, with low substrate concentrations, only low caproate production rates can be achieved resulting to low caproate titers, making a production process uneconomic. Furthermore, in ethanol fermentation broths the ethanol concentration ranges from 400 to $1800 \mathrm{mmol} / \mathrm{L}$, which is much higher than the initial ethanol level reported as substrate for caproate production (Kenealy et al., 1995; Jeon et al., 2010; Weimer and Stevenson, 2012; Vasudevan et al., 2014;

Weimer et al., 2015). Thus, in order to use the ethanol fermentation broth as substrate, a fermentation process for caproate production at higher ethanol concentrations needs to be developed.

In this study, the characteristics of caproate production from the diluted fermentation effluent with relatively high level of ethanol (up to $1000 \mathrm{mmol} / \mathrm{L}$ ) by Clostridium kluyveri were investigated. In addition, the effect of acetate and ethanol concentration on caproate production was explored. The results provide important supplementary information to the biosynthesis of caproate from industrial fermentation effluent.

\section{Material and methods}

\subsection{Preparation of inocula}


115 Clostridium kluyveri DSM 555 was purchased from the DSMZ (The Leibniz Institute

116 DSMZ - German Collection of Microorganisms and Cell Cultures, Braunschweig,

117 Germany), and was cultivated in DSM-52 medium. The medium was boiled for 1 min

118 and cooled to room temperature under $80 \% \mathrm{~N}_{2}$ and $20 \% \mathrm{CO}_{2}$ gas atmosphere, after

119 which $0.25 \mathrm{~g} / \mathrm{L} \mathrm{L}-\mathrm{Cysteine}-\mathrm{HCl} \cdot \mathrm{H}_{2} \mathrm{O}$ was added as reducing agent. The $\mathrm{pH}$ of the

120 medium was adjusted to 7.5 using $1 \mathrm{M} \mathrm{NaOH}$ and $1 \mathrm{M} \mathrm{HCl}$. Then, the reduced medium

121 was dispensed in $300 \mathrm{~mL}$ glass bottles with $100 \mathrm{~mL}$ working volume. All bottles were

122 sealed with rubber stoppers and aluminum caps to avoid gas leakage. The sealed bottles

123 were flushed with $80 \% \mathrm{~N}_{2}$ and $20 \% \mathrm{CO}_{2}$ for 30 min to provide the anaerobic

124 environment. Bottles were autoclaved and the medium was further supplemented with a

125 vitamin solution (DSM-503), $1 \mathrm{~g} / \mathrm{L}$ yeast extract and $20 \mathrm{~mL} / \mathrm{L}$ ethanol through a $0.2 \mathrm{um}$

126 membrane filter. Then, Clostridium kluyveri DSM 555 was inoculated into the bottles,

127 which were placed in a reciprocal shaker $\left(37^{\circ} \mathrm{C}, 150 \mathrm{rpm}\right)$ and incubated for $3-4$ days

128 until the bacteria entered the stationary phase. Subsequently, the bacteria was

129 transferred into fresh medium for another cultivation. Before being used in batch

130 experiments, pure culture of Clostridium kluyveri was transferred for over 3 times to

131 fully activate the bacteria and achieve a stable state.

$132 \quad 2.2$ Experimental setup

133 Batch experiments were conducted in $600 \mathrm{~mL}$ glass bottles with $100 \mathrm{~mL}$ working

134 volume, rubber stoppers and aluminum caps were used to avoid gas leakage from the

135 bottles. Acetate and ethanol was used as sole carbon sources, the composition of carbon

136 source and additional electron donor in different batch tests is shown in Table 1. For the 
137

138

139

140

141 previous study (Weimer and Stevenson, 2012).

142

143

\section{Table 1 Experimental set up of the different batch tests.}

\subsection{Analytical methods}

158 Cell dry weight was measured according to Standard Methods (APHA, 1995). The pH 
159

160

161

162

163

164

165

166

168

169

170

171 for approx. 40 hours before it entered the stationary phase (Fig.1). Maximum cell dry

was measured by PHM99 LAB pH meter connected to the Gel $\mathrm{pH}$ electrode

(pHC3105-8, Radiometer analytical). Hydrogen was analyzed by GC-TCD (Mikrolab,

Aarhus A/S, Denmark) fitted with a $4.5 \mathrm{~m} \times 3 \mathrm{mms}-\mathrm{m}$ stainless column packed with

Molsieve SA (10/80). The temperatures of the injector, detector and oven were 190, 110,

and $190{ }^{\circ} \mathrm{C}$, respectively. $\mathrm{N}_{2}$ was used as carrier gas. Concentration of alcohols and VFA

was analyzed by a gas-chromatograph (HP5890 series II) equipped with a FFAP fused

silica capillary column (30m 0.53 mmi.d. film thickness $1.5 \mathrm{~mm})$ and a flame

ionization detector. The carrier gas was $\mathrm{N}_{2}$.

\section{Results and discussion}

\subsection{Growth of Clostridium kluyveri}

C. kluyveri (DSM 555) was cultivated in DSM-52 medium. Initially it showed a lag

phase of approx. 30 hours, and then entered the exponential growth phase which lasted

weight of $0.62 \mathrm{~g} / \mathrm{L}$ was obtained after $74 \mathrm{~h}$ of cultivation. Microbial growth rate of

$17313.16 \mathrm{mg} / \mathrm{L} / \mathrm{h}$ was obtained. Similar, growth process was observed by Stadtman and

174 Barker (1949). Besides, shorter lag time of $16 \mathrm{~h}$ was obtained by Thauer et al. (1968),

175 with maximum cell dry weight of less than $0.025 \mathrm{~g} / \mathrm{L}$ at $48 \mathrm{~h}$. The short lag time and low

176 cell dry weight obtained by Thauer et al. (1968) may due to lower initial ethanol

177 concentration of $11.5 \mathrm{~g} / \mathrm{L}$, resulting in lower inhibition of growth, while supplying

178 lower amount of carbon source yielding in lower cell-biomass. Thus, the high cell

179 concentration and regular growth period indicated strain C. kluyveri was fully activated

180 and functioned well in present lab condition. 
Fig. 1 Growth curve of Clostridium kluyveri cultivated in DSM-52 medium

183

184

185

186

187

188

189

190

191

192

194

195

196

198 (2016) also observed that the increase of ethanol concentration from $0 \mathrm{~g} / \mathrm{L}$ to $20 \mathrm{~g} / \mathrm{L}$

199 resulted in increase of growth rates, and subsequently a decrease of the fermentation

200 duration, defined as the termination of both substrate consumption and VFA

201 generation, from around $22 \mathrm{~d}$ to $18 \mathrm{~d}$. However, despite that stagnation of growth it

\subsection{Effect of substrate composition on caproate production}

In batch fermentation with $50 \mathrm{mmol} / \mathrm{L}(2.3 \mathrm{~g} / \mathrm{L})$ acetate and $50 \mathrm{mmol} / \mathrm{L}(3 \mathrm{~g} / \mathrm{L})$

ethanol as initial substrate concentrations, caproate was produced by $C$. kluyveri at 37

${ }^{\circ} \mathrm{C}$ and initial $\mathrm{pH}$ 7.5. Fig. 2 depicts the time course of microbial growth, $\mathrm{pH}$ change,

substrate utilization and formation of VFA during the fermentation process in 30 days.

As shown in Fig. 2A, there was a long lag phase of 6 days, before the bacteria entered the exponential growth phase. Microbial growth rate of $0.80 \mathrm{mg} / \mathrm{L} / \mathrm{h}$ and maximum cell dry weight of $0.28 \mathrm{~g} / \mathrm{L}$ was obtained at $20 \mathrm{~d}$, and remained stable for the remaining 10 days. The microbial growth rate and cell dry weight obtained in batch fermentation were $94 \%$ and $55 \%$ lower in comparison with the bacteria cultivated in DSM-52 medium. The slower growth rates observed may be due to the lower initial substrate concentration used in batch fermentation than bacteria cultivation process, indicating that the substrate concentration was below the saturation concentration to achieve maximum growth rates according to Monod growth model. Lonkar et al. was observed that not all substrates were consumed, probably due to product 
203

204

205

inhibition or due to $\mathrm{pH}$ decrease. Accompanied with the microbial growth, $\mathrm{pH}$ decreased gradually from 7.5 to 5.7 due to the accumulation of VFA.

Studies have proved that the fermentative caproate production process was very sensitive to $\mathrm{pH}$. Kenealy et al. (1995) found that substrate consumption was inhibited when $\mathrm{pH}$ decreased at around 5.5, and caproate production can be significantly increased through controlling $\mathrm{pH}$ at around 6.8. Agler et al. (2012) and Vasudevan et al. (2014) figured out that caproate could be toxic to microbes when $\mathrm{pH}$ was under 5.5.

Coma et al. (2016) examined the detrimental effect of acidic environment ( $\mathrm{pH} \leq 4.5-5)$

to $C$. kluyveri. Thus, controlling operational $\mathrm{pH}$ at a near-neutral range can be necessary for ahieving a higher substrate degradation and caproate production rate.

As shown in Fig. 2B, substrate consumption and VFA production was terminated in 20 h. Concentration of caproate, burytate and valerate produced were $2.82 \mathrm{~g} / \mathrm{L}, 1.54$ $\mathrm{g} / \mathrm{L}$ and $0.31 \mathrm{~g} / \mathrm{L}$, respectively. The formation of VFA was consistent with the cell growth. The first $10 \mathrm{~h}$ only low VFA production as observed, and therefore was assumed that microbial growth was in lag phase. When the exponential growth phase was initiated, significant increase in VFA production was obtained. Formation of VFA ceased with termination of cell growth. Same time course was obtained by Thauer et al. (1968). During the fermentation process, both acetate and ethanol concentrations decreased gradually from the beginning of fermentation process and removal efficiency of $72.5 \%$ and $85.2 \%$ were obtained at the end of batch run. However, in other studies, substrate was consumed simultaneously with the formation of VFA (Thauer et al., 1968; Kenealy et al., 1995; Weimer and Stevenson, 2012; Jeon et al., 
242 To explore the effect of initial acetate/ethanol ratio on caproate production, batch tests

243 with only acetate and ethanol at different acetate/ethanol ratios $(8: 2,7: 3,5: 5,3: 7,2: 8)$,

244 as carbon sources were conducted (Table 1, batch 1). Hydrogen was added as extra

245 electron donor. VFA and alcohols concentration at different acetate/ethanol ratios is 246 shown in Fig. 3. 
247 It can be seen that caproate production was lower than $1 \mathrm{~g} / \mathrm{L}$ when acetate/ethanol was

248 higher than 7:3. However, it increased dramatically to $3.02 \mathrm{~g} / \mathrm{L}$ when acetate/ethanol

249 decreased to 5:5, and achieved the highest concentration of $3.11 \mathrm{~g} / \mathrm{L}$ when

250 acetate/ethanol was decreased to 3:7. Many studies have also observed the negative

251 correlation between caproate production and acetate/ethanol ratio. Liu et al. (2016)

252 found that caproate production can be enhanced through decreasing the

253 acetate/ethanol ratio from 2:1 to 1:3. Weimer and Stevenson (2012) observed linear

254 decrease of caproate formation with the reduction of acetate/ethanol ratio from 5 to 0.

255 However, in this study, both caproate and butyrate production decreased with the

256 further increase of the ethanol share, while the concentration of valerate remained at a

257 high level, indicating that acetate was necessary for caproate production, reduction of

258 acetate in substrate can also inhibit the fermentative caproate production process.

259 Similarly Diender et al. (2016) found that the production of medium-chain fatty acids

260 can be significantly stimulated by the presence of acetate. However, the specific

261 function of acetate is not clear yet.

262 As to the other VFA, butyrate showed a similar trend with caproate. Propionate

263 production was favored at high acetate concentration, while valerate production was

264 promoted at high ethanol concentration. Wallace et al. (2004) found that both

265 propionate and butyrate can be turned into valerate and caproate with ethanol as

266 electron donor. Thus, it is reasonable that the remaining propionate and butyrate

267 concentration decreased with the increase of added ethanol. For the tests with ethanol

268 as sole carbon source, valerate production was dramatically affected by the addition of 
hydrogen.

Fig. 3 Volatile fatty acids production at different acetate/ethanol ratios

273 Fig. 4 shows the change of hydrogen content in each bottle. Only a little change of hydrogen content was observed in all test groups. For the test groups with acetate/ethanol ratio over 5:5, hydrogen content showed a little increase in $10 \mathrm{~d}$ and then decreased in $30 \mathrm{~d}$. Seedorf et al. (2008) and Ding et al. (2010) have showed that both hydrogen and caproate can be produced from acetate and ethanol by Clostridium kluyveri. Hydrogen has been proved to be able to act as electron donor for both hexanol and ethanol production from acetate (Spirito et al., 2014; Ding et al. 2010; Mu and $\mathrm{Yu}, 2006)$, however, the results showed that little hydrogen was consumed during

281 the fermentation process, which may because of the thermodynamic bottleneck for the 282 hydrogen to be used as electron donor (Gonzálezcabaleiro et al. 2013).

283 For the tests with acetate/ethanol ratio less than 1:1, the hydrogen content increased 284 along the fermentation process. Although the $\Delta G^{0}$ of hydrogen as electron donor is 285 much more negative than ethanol as electron donor (Equation 1-3.4), the results 286 showed that ethanol is more easily consumed as electron donor than hydrogen. This 287 may due to the high mass transfer resistance between hydrogen and reaction phase.

288 The results indicate that at high ethanol levels, no additional electron donors are 289 needed for the caproate production process. Same conclusion was also made by Liu et 290 al. (2016) that the electron donor was sufficient for the chain elongation reaction 
when acid/alcohol ratio was less than 1:2.

Fig. 4 Change of hydrogen content along the fermentation process in different

294

\section{batches}

\subsection{Caproate production from high ethanol concentration wastewater}

To explore the possibility for caproate production from high ethanol concentration wastewaters, $500 \mathrm{mmol} / \mathrm{L}(23 \mathrm{~g} / \mathrm{L})$ ethanol along with $50 \mathrm{mmol} / \mathrm{L}(3 \mathrm{~g} / \mathrm{L})$ acetate were used as carbon source. It can be seen from Fig. 5A that bacteria grew very fast in the medium containing high ethanol concentration. Cell dry weight achieved $0.75 \mathrm{~g} / \mathrm{L}$ in 3 d cultivation. Subsequently the fast growing cells formed flocks in the solution, making determination of the cell concentration through a small amount of sample unreliable due to the inhomogeneity issues. However, we could also observe that the microbes entered exponential growth directly without experiencing a lag phase, and the fermentation process terminated in $5 \mathrm{~d}$. Microbial growth rate of $12.67 \mathrm{mg} / \mathrm{L} / \mathrm{h}$ was obtained. Comparing with the batch tests using $23 \mathrm{~g} / \mathrm{L}$ ethanol and $3 \mathrm{~g} / \mathrm{L}$ acetate as substrate, both microbial growth rate and maximum cell dry weight were significantly enhanced. Similar to microbial growth, $\mathrm{pH}$ dropped from $\mathrm{pH} 7.5$ to $\mathrm{pH}$ 6.2 in $3 \mathrm{~d}$, and then remained constant at around $\mathrm{pH} 6.1$.

As shown in Fig. 5B, acetate and ethanol decreased with the microbial growth. After three days, acetate concentration decreased to an undetectable level and ethanol was at around $15 \mathrm{~g} / \mathrm{L}$. Butyrate increased in first $36 \mathrm{~h}$, showing that acetate and ethanol were 
313 first converted to butyrate (Equation 3). Subsequently, butyrate decreased to under 5

$314 \mathrm{~g} / \mathrm{L}$ due to elongation of butyrate to caproate (Equation 3.1, 3.3) (Mu and $\mathrm{Yu}, 2006$;

315 Ding et al., 2010). Caproate concentration increased significantly in first three days

316 and highest concentration of $8.42 \mathrm{~g} / \mathrm{L}$ was obtained. It can be seen that the conversion

317 efficiency (Consumed amount /Original amount) of ethanol was around $48 \%$. Lonkar

318 et al. (2016) reported that ethanol conversion efficiency decreased from over $80 \%$ to

319 less than $25 \%$ when initial ethanol concentration increased from 5 to $40 \mathrm{~g} / \mathrm{L}$. The

320 termination of fermentation process may be due to the acetate depletion, since it has

321 been proposed that the chain elongation reaction needs to be stimulated by acetate.

322 Another possible reason could be product inhibition. Different maximum achieved

323 caproate concentrations through microbial fermentation, have been reported in the

324 literature and were in the range from $0.8 \mathrm{~g} / \mathrm{L}$ to $8.6 \mathrm{~g} / \mathrm{L}$ (Steinbusch et al., 2011;

325 Weimer and Stevenson, 2012; Jeon et al., 2013; Vasudevan et al., 2014; Weimer et al.,

326 2015; Ganigué et al., 2016; Liu et al., 2016; Lonkar et al., 2016). To further enhance

327 the caproate production, in situ recovery of the formed caproate during the

328 fermentation process may enhance the final caproate yield (Jeon et al., 2013).In

329 summary, $23 \mathrm{~g} / \mathrm{L}$ ethanol showed no inhibition on $C$. kluyveri, and the high substrate

330 concentration stimulated both microbial growth and fermentative caproate production.

332 Fig. 5 Volatile fatty acids production from acetate $(50 \mathrm{mmol} / \mathrm{L})$ and ethanol (500

$333 \mathbf{m m o l} / \mathbf{L})$ 
335 Caproate production from different ethanol concentrations (Table 1, batch 2) was

336 studied. Since little hydrogen was used in batch tests with low ethanol concentration,

337 no hydrogen was added as electron donor in this test. VFA production in different test

338 groups is shown in Fig. 6.

339 Similar with the results obtained in 3.2, low concentrations of caproate was produced

340 from sole acetate. Then, with the increase of ethanol concentration from $9.2 \mathrm{~g} / \mathrm{L}$ to 23

$341 \mathrm{~g} / \mathrm{L}$, acetate/ethanol ratio decreased from infinity to $1: 10$, caproate production

342 increased from 7.66 to $8.42 \mathrm{~g} / \mathrm{L}$. However, Gildemyn et al. (2017) obtained more

343 efficient caproate production with acetate/ethanol ratio 1:3 instead of 1:10 in

344 continuous fermentation, indicating the optimal substrate composition is affected by

345 the operation mode. Then, with the further increase of ethanol concentration to 36.8

$346 \mathrm{~g} / \mathrm{L}$, caproate concentration decreased to $4.93 \mathrm{~g} / \mathrm{L}$. On the other hand, valerate showed

347 a significant increase from $3.66 \mathrm{mg} / \mathrm{L}$ to $148.49 \mathrm{mg} / \mathrm{L}$ with the increase of ethanol

348 concentration. The results indicate that metabolic pathway was changed from caproate

349 formation to valerate production in C. kluyveri when ethanol was over $23 \mathrm{~g} / \mathrm{L}$.

350 Butyrate production decreased from 2.56 to $0.23 \mathrm{~g} / \mathrm{L}$ with the decrease of

351 acetate/ethanol ratio, which was because less butyrate was formed with the decrease

352 of acetate while more butyrate was turned to caproate with the increase of ethanol.

353 When ethanol concentration was further increased to $46 \mathrm{~g} / \mathrm{L}$, little VFA production

354 was observed, indicating that C. kluyveri was inhibited. Lonkar et al. (2016) also

355 observed no chain elongation when ethanol concentration was over $40 \mathrm{~g} / \mathrm{L}$. Different

356 from the results obtained in 3.2, no propionate was detected in all the test groups, 
which may because of the absence of hydrogen.

Fig. 6 Volatile fatty acids production at different acetate/ethanol ratios

\section{Conclusions}

362 Caproate production through chain elongation by Clostridium kluyveri was conducted,

363 and high ethanol concentrations (up to $46 \mathrm{~g} / \mathrm{L}$ ) was for the first time explored in this

364 study. The results showed great effect of acetate/ethanol ratios ranged from 1:40 to 4:1

365 on biosynthesis of caproate. Caproate production can be enhanced through the

366 increase of ethanol concentration. Follow-up studies can focus on optimizing the

367 fermentation process considering the interactions between different parameters, like

$368 \mathrm{pH}$, acetate/ethanol ratio and temperature; exploring more strains that are capable of

369 high efficient chain elongation as well as high tolerance to ethanol and final products.

370 Further development of innovative bioprocess that could further convert the caproate

371 to the corresponding alcohol would promote the wide application of the technology.

\section{Acknowledgement}

374 The authors thank the technical assistance by Hector Gracia with analytical

375 measurements. This research is supported financially by the Danish Council for

376 Independent Research (DFF-1335-00142) and Novo Nordisk Foundation

377 (NNF16OC0021568). The authors would like to thank the financial support provided

378 by China Scholarship Council (CSC). 
379

380

381

382

\section{References:}

1. Agler MT, Spirito CM, Usack JG, Werner JJ, Angenent LT. 2012. Chain elongation with reactor microbiomes: upgrading dilute ethanol to medium-chain carboxylates. Energ Environ Sci. 5: 8189-8192.

2. Agler MT, Spirito CM, Usack JG, Werner JJ, Angenent LT. 2014. Development of a highly specific and productive process for n-caproic acid production: applying lessons from methanogenic microbiomes. Water Science \& Technology. 69: 62-68.

3. Agler MT, Wrenn BA, Zinder SH, Angenent LT. 2011. Waste to bioproduct conversion with undefined mixed cultures: the carboxylate platform. Trends Biotechnol. 29: 70-78.

4. APHA. 1995. Standard methods for the examination of water and wastewater. Washington DC, USA: American Public Health Association.

5. Bornstein BT, Barker HA. 1948. The energy metabolism of Clostridium kluyveri and the synthesis of fatty acids. J Biol Chem. 172: 659-69.

6. Brar KK, Kaur S, Chadha BS. 2016. A novel staggered hybrid SSF approach for efficient conversion of cellulose/hemicellulosic fractions of corncob into ethanol. Renew Energ. 98: 16-22.

7. Butkus MA, Hughes KT, Bowman DD, Liotta JL, Jenkins MB, Labare MP. 2010. Inactivation of Ascaris suum by Short-Chain Fatty Acids. Appl Environ Microb.

$$
\text { 77: } 363-366 .
$$

8. Coma M, Vilchez-Vargas R, Roume H, Jauregui R, Pieper DH, Rabaey K. 2016. 
9. Desbois AP. 2012. Potential applications of antimicrobial fatty acids in medicine, agriculture and other industries. Recent patents on anti-infective drug discovery. 7 : $111-22$

10. Diender M, Stams AJM, Sousa DZ. 2016. Production of medium-chain fatty acids and higher alcohols by a synthetic co-culture grown on carbon monoxide or syngas. Biotechnol Biofuels. 9: 82.

11. Ding H, Tan GA, Wang J. 2010. Caproate formation in mixed-culture fermentative hydrogen production. Bioresour Technol. 101: 9550-9559.

12. Dworkin M, Falkow S, Rosenberg E, Schleifer K, Stackebrandt E. 2006. The Prokaryotes: Vol. 4: Bacteria: Firmicutes, Cyanobacteria: Springer Science \& Business Media.

13. Ganigué R, Sánchez-Paredes P, Bañeras L, Colprim J. 2016. Low fermentation pH is a trigger to alcohol production, but a killer to chain elongation. Front Microbiol.

416 14. Gildemyn S, Molitor B, Usack JG, Nguyen M, Rabaey K, Angenent LT. 2017.

417 Upgrading syngas fermentation effluent using Clostridium kluyveri in a continuous 418 fermentation. Biotechnol Biofuels. 10: 83.

419 15. Gonzálezcabaleiro R, Lema JM, Rodríguez J, Kleerebezem R. 2013. Linking thermodynamics and kinetics to assess pathway reversibility in anaerobic bioprocesses. Energ Environ Sci. 6 (12): 3780. 
422

423

16. Grootscholten TIM, Steinbusch KJJ, Hamelers HVM, Buisman CJN. 2013. Improving medium chain fatty acid productivity using chain elongation by reducing the hydraulic retention time in an upflow anaerobic filter. Bioresour Technol; 136: 735-738.

17. Harvey BG, Meylemans HA. 2014. 1-Hexene: a renewable C6 platform for full-performance jet and diesel fuels. Green Chem. 16: 770-776.

18. Hu X, Du H, Xu Y. 2015. Identification and quantification of the caproic acid-producing bacterium Clostridium kluyveri in the fermentation of pit mud used for Chinese strong-aroma type liquor production. Int J Food Microbiol. 214: $116-122$.

19. Isom CE, Nanny MA, Tanner RS. 2015. Improved conversion efficiencies for $\mathrm{n}$-fatty acid reduction to primary alcohols by the solventogenic acetogen “Clostridium ragsdalei”. J Ind Microbiol Biot. 42: 29-38.

20. Jeon BS, Kim BC, Um Y, Sang BI. 2010. Production of hexanoic acid from D-galactitol by a newly isolated Clostridium sp. BS-1. Appl Microbiol Biotechnol. 88: 1161-7.

21. Jeon BS, Moon C, Kim BC, Kim H, Um Y, Sang BI. 2013. In situ extractive fermentation for the production of hexanoic acid from galactitol by Clostridium sp. BS-1. Enzyme Microb Tech. 53: 143-151.

22. Kenealy WR, Cao Y, Weimer PJ. 1995. Production of caproic acid by cocultures of ruminal cellulolytic bacteria and Clostridium kluyveri grown on cellulose and ethanol. Appl Microbiol Biotechnol. 44: 507-13. 
444

445

446

447

448

450

23. Kenealy WR, Waselefsky DM. 1985. Studies on the substrate range of Clostridium kluyveri ; the use of propanol and succinate. Archives Microbiol, 141: 187-194.

24. Kucek LA, Nguyen M, Angenent LT. 2016. Conversion of l-lactate into n-caproate by a continuously fed reactor microbiome. Water Res; 93: 163-171.

25. Lee WS, Chua ASM, Yeoh HK, Ngoh GC. 2014. A review of the production and applications of waste-derived volatile fatty acids. Chem Eng J. 235: 83-99.

26. Levy PF, Sanderson JE, Kispert RG, Wise DL. 1981. Biorefining of biomass to liquid fuels and organic chemicals. Enzyme Microb Tech. 3: 207-215.

27. Liu Y, Lü F, Shao L, He P. 2016. Alcohol-to-acid ratio and substrate concentration affect product structure in chain elongation reactions initiated by unacclimatized inoculum. Bioresour Technol. 218: 1140-1150.

28. Lonkar S, Fu Z, Holtzapple M. 2016. Optimum alcohol concentration for chain elongation in mixed-culture fermentation of cellulosic substrate. Biotechnol Bioeng. 113: 2597-2604.

29. Mishra A, Sharma AK, Sharma S, Bagai R, Mathur AS, Gupta RP, Tuli DK. 2016. Lignocellulosic ethanol production employing immobilized Saccharomyces cerevisiae in packed bed reactor. Renew Energ. 98: 57-63.

30. Mu Y, Yu HQ. 2006. Biological hydrogen production in a UASB reactor with granules. I: Physicochemical characteristics of hydrogen-producing granules. Biotechnol Bioeng. 94: 980-987.

31. Perez JM, Richter H, Loftus SE, Angenent LT. 2013. Biocatalytic reduction of 
short-chain carboxylic acids into their corresponding alcohols with syngas fermentation. Biotechnol Bioeng. 110: 1066-1077.

32. Seedorf H, Fricke WF, Veith B, Bruggemann H, Liesegang H, Strittmatter A, metabolic features. Proc Natl Acad Sci USA. 105: 2128-33. elongation in anaerobic reactor microbiomes to recover resources from waste. Curr Opin Biotech. 27: 115.

34. Stadtman ER, Barker HA. 1949. Fatty acid synthesis by enzyme preparations of Clostridium kluyveri. VI. Reactions of acyl phosphates. J Biol Chem. 180: 1095-1115.

35. Steinbusch KJ, Hamelers HV, Plugge CM, Buisman CJ. 2011. Biological formation of caproate and caprylate from acetate: fuel and chemical production from low grade biomass. Energ Environ Sci. 4: 216-224.

481 36. Steinbusch KJJ, Arvaniti E, Hamelers HVM, Buisman CJN. 2009. Selective inhibition of methanogenesis to enhance ethanol and n-butyrate production through acetate reduction in mixed culture fermentation. Bioresour Technol. 100: 3261-3267. metabolism of Clostridium kluyveri. European J Biochem. 4: 173-180. 
syngas fermentation to n-caproate with reactor microbiomes. Bioresour Technol. 151: 378-382.

39. Wallace RJ. 2003. Eubacterium pyruvativorans sp. nov., a novel non-saccharolytic anaerobe from the rumen that ferments pyruvate and amino acids, forms caproate and utilizes acetate and propionate. Int J Syst Evol Micr. 53: 965-970.

40. Wallace RJ, Chaudhary LC, Miyagawa E, McKain N, Walker ND. 2004. Metabolic properties of Eubacterium pyruvativorans, a ruminal 'hyper-ammonia-producing' anaerobe with metabolic properties analogous to those of Clostridium kluyveri. Microbiol-SGM; 150 (9): 2921-2930.

41. Watt S, Sidhu HS, Nelson MI, Ray AK. 2007. Analysis of a model for ethanol production through continuous fermentation. Int J Chem React Eng. 49: 85-99.

42. Weimer PJ, Nerdahl M, Brand1 DJ. 2015. Production of medium-chain volatile fatty acids by mixed ruminal microorganisms is enhanced by ethanol in co-culture with Clostridium kluyveri. Bioresour Technol. 175: 97-101.

43. Weimer PJ, Stevenson DM. 2012. Isolation, characterization, and quantification of Clostridium kluyveri from the bovine rumen. Appl Microbiol Biot. 94: 461-466. C1 to C5 organic acids in anaerobic digestion. Water Res. 87: 112-118. production using gamma irradiated sludge as inoculum. Bioresour Technol. 200: 


\section{Legends}

512 Fig. 1 Growth curve of Clostridium kluyveri cultivated in DSM-52 medium

513 Fig. 2 Volatile fatty acids production from acetate $(50 \mathrm{mmol} / \mathrm{L})$ and ethanol (50

$514 \mathrm{mmol} / \mathrm{L})$

515 Fig. 3 Volatile fatty acids production at different acetate/ethanol ratios

516 Fig. 4 Change of hydrogen content along the fermentation process in different batches

517 Fig. 5 Volatile fatty acids production from acetate (50 mmol/L) and ethanol (500

$518 \mathrm{mmol} / \mathrm{L})$

519 Fig. 6 Volatile fatty acids production at different acetate/ethanol ratios

520 Table 1 Experimental set up of the different batch tests.

521 


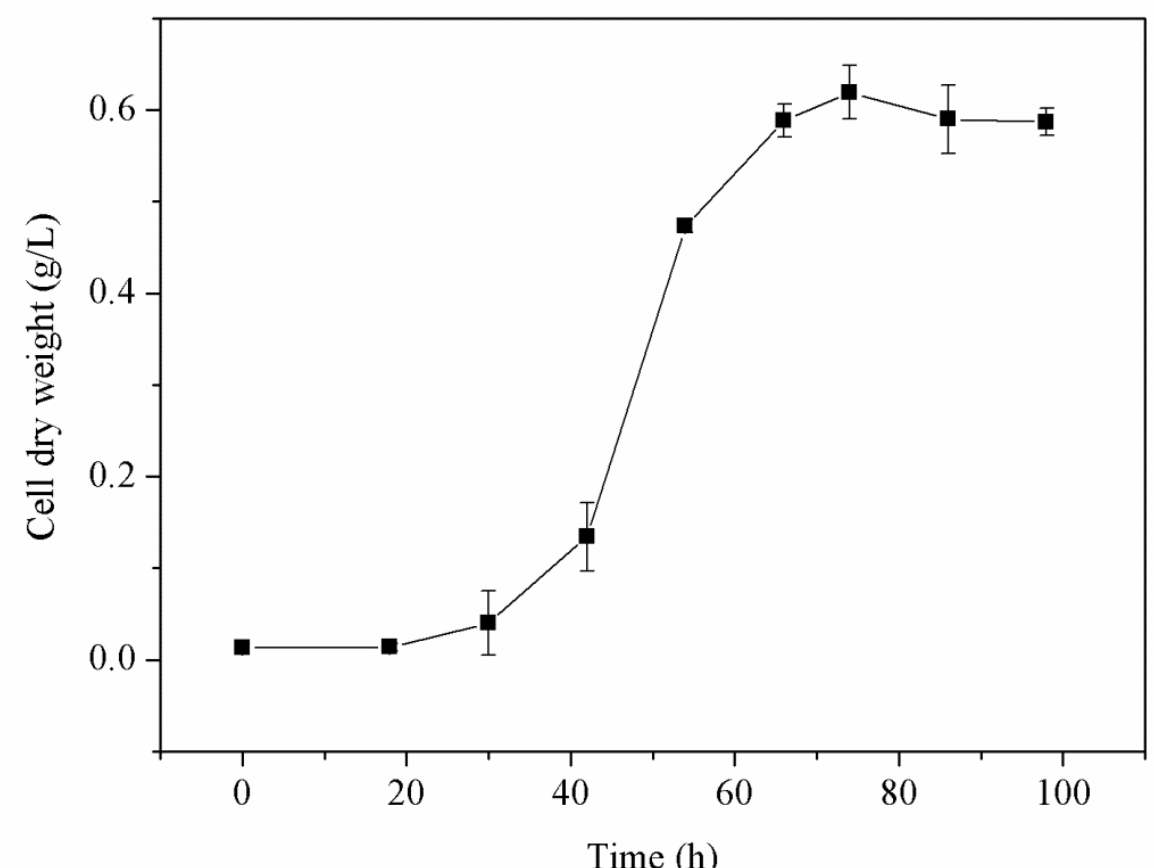

522

Time (h)

523

524 Fig. 1

525

526 

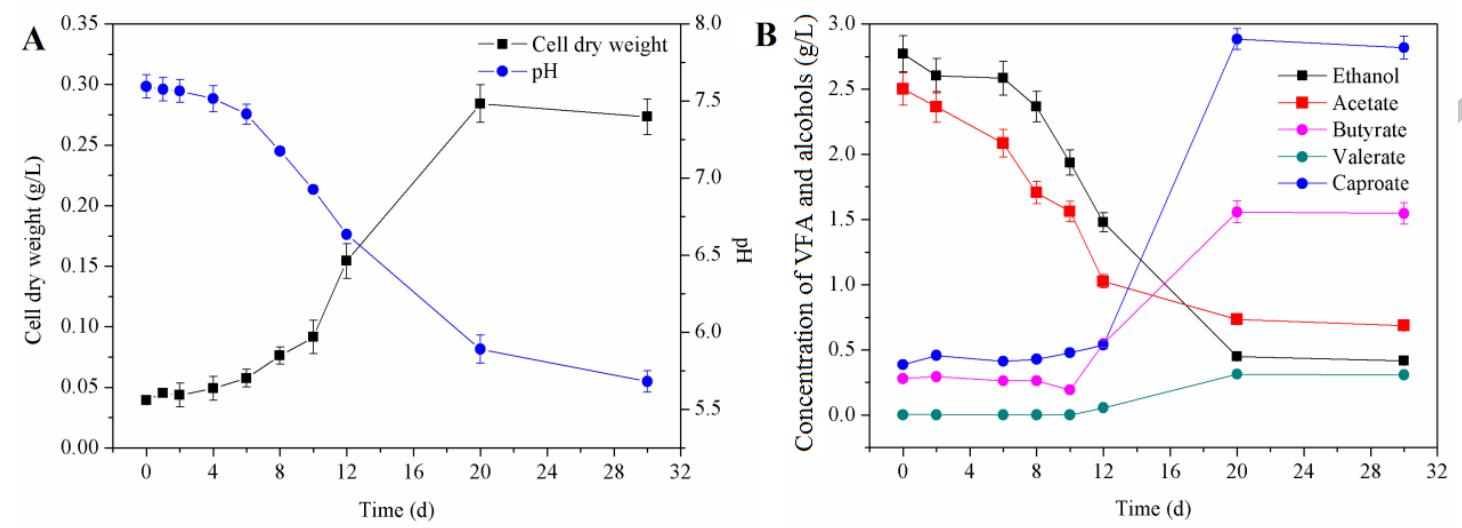

530

531 Fig. 2

532

533 


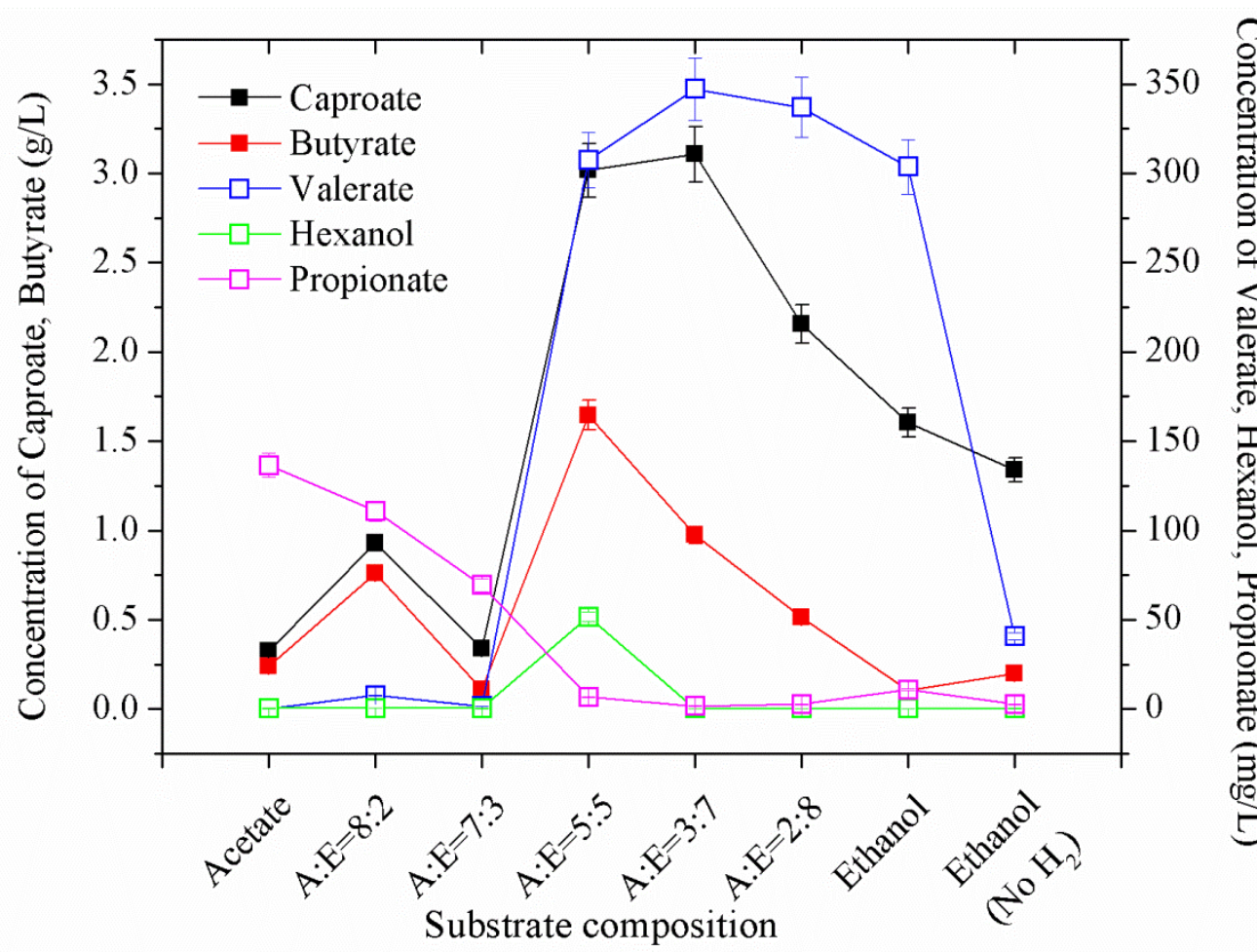

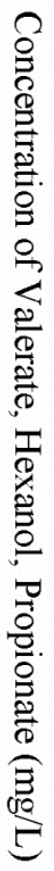

$536 \quad$ Fig. 3

537 
538

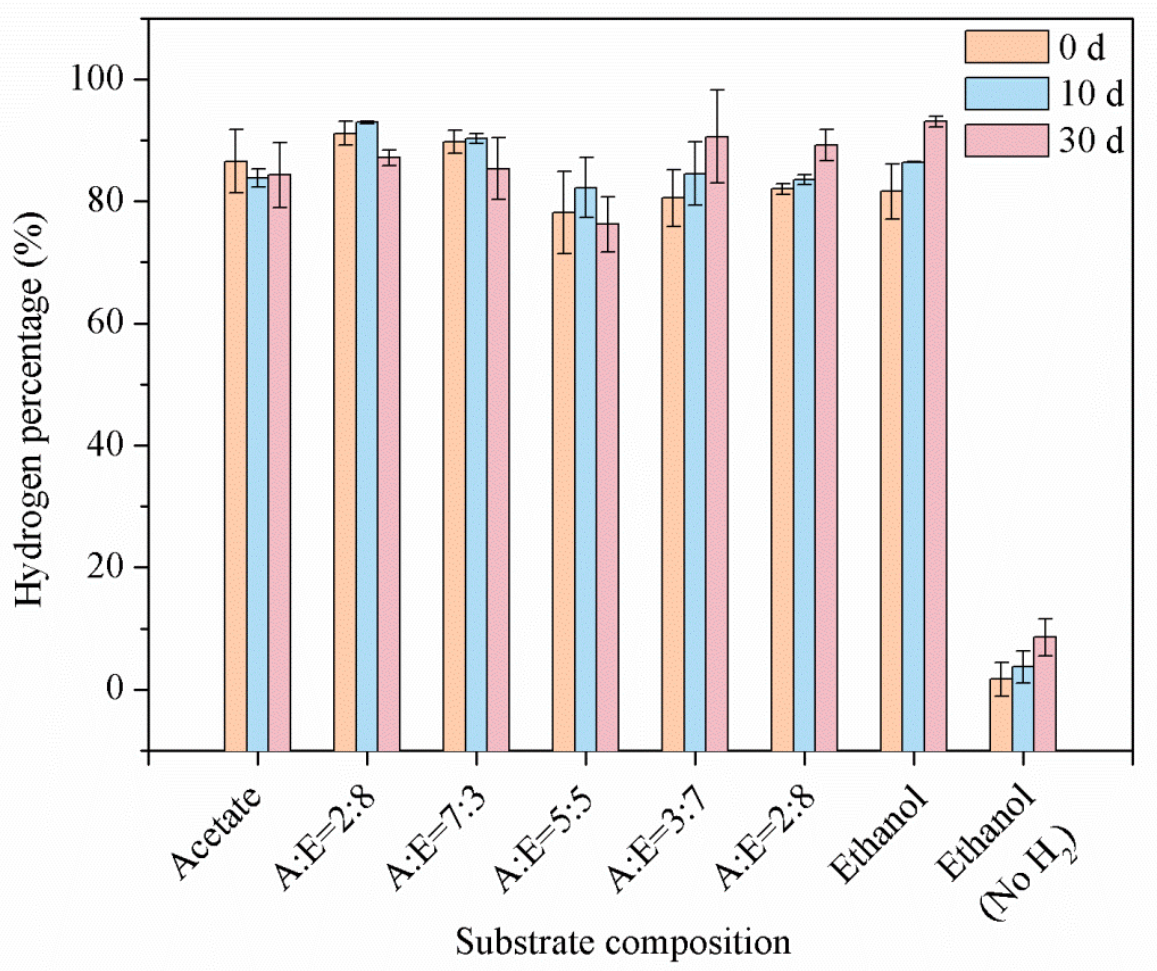

539

540

$541 \quad$ Fig. 4

542

543 

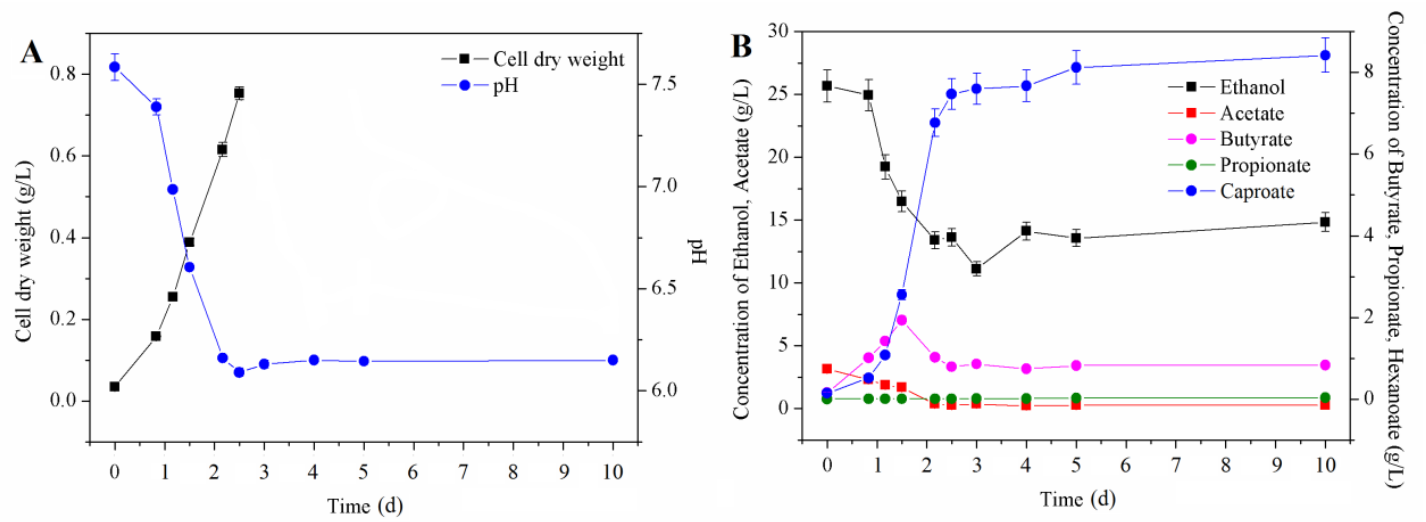

547

548

Fig. 5

549

550 


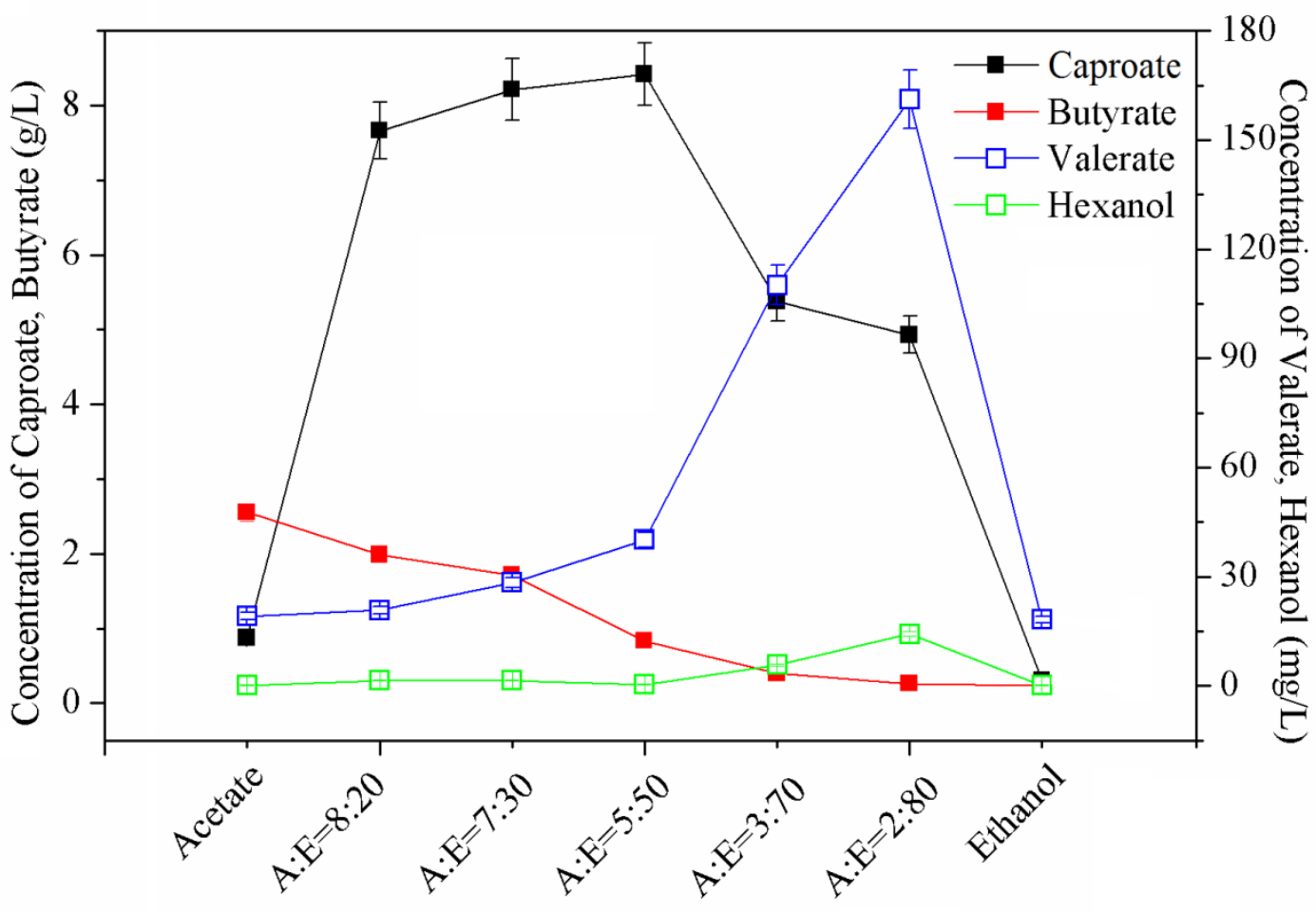

552

Substrate composition

553 Fig. 6

554

555 
Table 1 Composition of carbon source and addition of hydrogen in different batch

tests

\begin{tabular}{|c|c|c|c|}
\hline \multirow[t]{2}{*}{ Batch } & \multicolumn{2}{|c|}{ Carbon source $(\mathrm{mmol} / \mathrm{L})$} & Additional electron donor \\
\hline & Acetate & Ethanol & $\mathrm{H}_{2}(\mathrm{~mL})$ \\
\hline \multicolumn{4}{|l|}{ Batch 1} \\
\hline Acetate & 100 & 0 & 480 \\
\hline$A: E=8: 2$ & 80 & 20 & 480 \\
\hline$A: E=7: 3$ & 70 & 30 & 480 \\
\hline$A: E=5: 5$ & 50 & 50 & 480 \\
\hline$A: E=3: 7$ & 30 & 70 & 480 \\
\hline$A: E=2: 8$ & 20 & 80 & 480 \\
\hline Ethanol & 0 & 100 & 480 \\
\hline Ethanol( $\left.\mathrm{No} \mathrm{H}_{2}\right)$ & 0 & 100 & 0 \\
\hline \multicolumn{4}{|l|}{ Batch 2} \\
\hline Acetate & 100 & 0 & 0 \\
\hline$A: E=8: 20$ & 80 & 200 & 0 \\
\hline$A: E=7: 30$ & 70 & 300 & 0 \\
\hline A:E & 50 & 500 & 0 \\
\hline$A: E=3: 70$ & 30 & 700 & 0 \\
\hline$A: E=2: 80$ & 20 & 800 & 0 \\
\hline Ethanol & 0 & 1000 & 0 \\
\hline
\end{tabular}




\section{Highlights}

563 - The composition and yield of VFA was influenced by acetate/ethanol ratio.

564 - Ethanol was used in priority as electron donor than hydrogen.

565 - High carbon source concentration enhanced caproate production.

566 - Ethanol concentration over $700 \mathrm{mM}$ inhibited biosynthesis process.

567

568 - Highest caproate concentration was achieved at acetate/ethanol ratio 1:10

569 


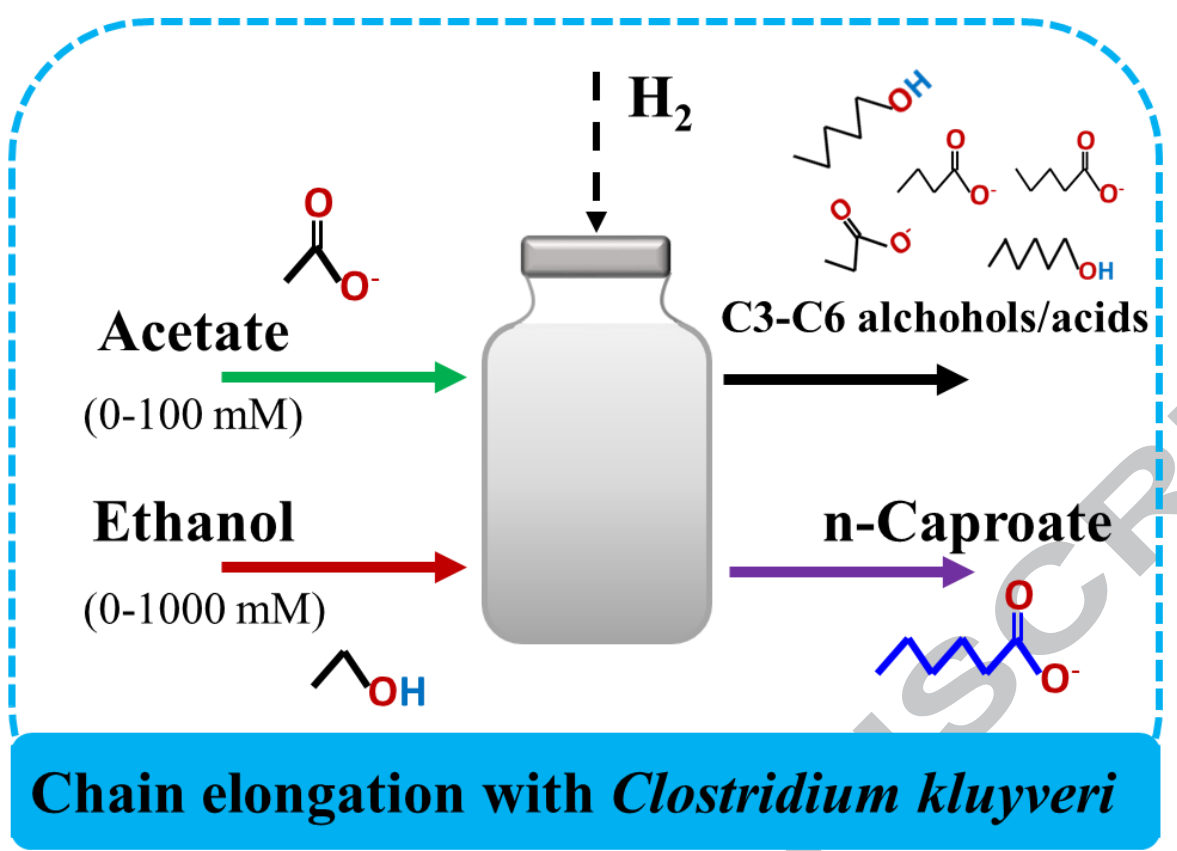

